\title{
INVENTARIO DE LA BIBLIOTECA DE D. NICOLAS PRO, ILUSTRADO ALICANTINO DEL SIGLO XVIII
}

\author{
Por Joaquin SAEZ VIDAL \\ I. N. B. "Figueras Pacheco"
}

El tema de este trabajo está centrado en el análisis del inventario de la biblioteca de un personaje representativo de la correinte ilustrada en nuestra ciudad. Nos referimos a quien fue en los años finales del siglo XVIII secretario del Ayuntamiento de Alicante: D. Nicolás Pró.

El hallazgo de dicho inventario bibliográfico, por otra parte, lo hemos localizado en un legajo existente en el Archivo Municipal alicantino, en el cual se contiene la referencia explícita de los bienes dejados a la muerte de D. Nicolás Pro, en 1787, a sus herederos(1).

El conocimiento de dicho fondo bibliográfico creemos puede resultar de utilidad por cuanto nos permite sumergirnos en las fuentes que estimularian el proceso formativo del pensamiento del lector. Revelaria, asi mismo, el bagaje cultural de que dispondría su propietario. Con todo, el inventario de la biblioteca de D. Nicolás Pro, como la de cualquier otra, no supone en modo alguno que la relación de libros que allí aparecen se identifique exclusivamente con el campo de lecturas de dicho señor, ni siquiera con el total de libros que pudiera haber acumulado. Hemos comprobado a este respecto que nuestro autor dispuso igualmente de otros volúmenes, algunos no aparecidos en el inventario, que periódicamente le enviaba desde Madrid D. Simón Gómez Pérez.

Sabemos, merced a la existencia de testimonios documentales aparecidos en el Archivo Municipal, de continuos encargos para la adquisición 
de ejemplares en la capital de la nación. Hubo casos, como más adelante veremos, en que la remisión de obras de determinados autores como Grocio, Montesquieu o Brucker, por él solicitadas, no fue posible por estar incluídos en la lista de autores prohibidos(2).

Asi y todo pensamos que al dar a conocer el conjunto de obras reunidas por el Sr. Pró lo que parece desprenderse claramente es que a través de ellas se patentiza la adecuación de su pensamiento con las tendencias culturales más avanzadas de su época.

Nuestro propósito al detallar la lista de libros consistirá además en destacar el decisivo papel que en el proceso de incorporación al pensamiento moderno por parte de D. Nicolás Pró va a ejercer la figura del erudito de Oliva D. Gregorio Mayáns.

Dicho magisterio adquiere consistencia al examinar el contenido de los libros que forman la biblioteca del alicantino. En relación con esto llama la atención el hecho de que la mayor parte de los títulos se hallan en una coincidente línea ideológica a la manifestada por Mayáns. Hay, pues, un mismo espíritu reformista que puede concretarse en los siguientes rasgos: manifiesta actitud crítica orientada al campo histórico; rechazo de toda opinión basada en los prejuicios o la ignorancia; vuelta al humanismo -herencia del influjo de Martí-; revalorización de los autores clásicos españoles e incluso del propio idioma español; búsqueda de una religiosidad más profunda, inspirada menos en ritos que en una honda reforma interior; familiarización con los tratados más valiosos del derecho y de la jurisprudencia, etc. Elementos todos ellos que en líneas generales constituyen el centro y el eje sobre los que gira la mentalidad renovadora de Mayáns.

Una vez hechas estas precisiones preliminares pasamos a ocuparnos del catálogo del inventario bibliográfico de D. Nicolás Pró. Este se compone de los siguiente títulos, que a continuación trascribimos, con indicación del número de tomos de que se compone cada obra y el valor estimado de las mismas:

..."Otrosí recae en dicha herencia los libros siguientes justipreciados por sujeto inteligente

TOSCA: Compendio Matematico, ocho tomos, octavo mayor, por ocho libras.

MARTINEZ: Filosofia Steptica, un tomo en quarto, por ocho sueldos.

BOSSUET: Potestad eclesiastica, seis tomos en quarto, quatro libras.

BOSSUET: Catesismo de la doctrina Christiana, un tomo en quarto pergamino, trece sueldos y quatro.

Ensayos para la historia de Artes y Siensias, un tomo en quarto, diez sueldos. 
ECHART: Diccionario Geografico, tres tomos, quarto, una libra doce sueldos.

ROLLIN: Historia antigua, trece tomos, quarto, siete libras.

ROLLIN: Historia de Artes y Siensias, tres tomos, quarto, dos libras.

ROLLIN: Metodo de estudiar las Bellas Letras, tres libras. y ocho.

ROLLIN: Historia del Cielo, dos tomos, quarto, una libra, seis sueldos

Espectáculo de la Naturaleza, con láminas, diez y seis tomos, doce libras.

Calepino de Salas, un tomo, en quarto, pergamino, una libra, seis sueldos y ocho.

BARBADIÑO: Metodo de estudiar, quatro tomos, quarto, una libra, seis sueldos y ocho.

VERNEl: De re logica, un tomo en quarto por diez y seis sueldos.

VERNEI: De Metafisica, ocho sueldos.

Historia del establecimiento de la Iglesia, seis tomos en quarto, quatro libras.

MARCIAL: Epigramas, cum notu ad usum Delfini, un tomo quarto mayor, una libra, seis sueldos y ocho.

Año Christiano, en frances, a saber los doce meses, quatro tomos de fiestas movibles y uno de la vida de Jesu Cristo y de la Virgen, todo diez y siete tomos en octavo, pasta, doce libras.

Monarquia ebrea por el MARQUES DE SAN FELIPE, dos tomos en quarto, una libra, doce suldos.

Exercicios de RODRIGUEZ, dos tomos en quarto, una libra.

CALATAYUD: Misiones y Sermones y una doctrina práctica, tres tomos en quarto, una libra doce sueldos. quatro.

MAS: su Filosofía, quatro tomos en octavo, una libra seis sueldos y

VIRGILIO, ad usum Delfini, un tomo en quarto, en pasta, dos libras. libras.

CICERON: Epistolas ad usum Delfini, un tomo en quarto, pasta, dos

CICERON: Oraciones ad usum Delfini, tres tomos en quarto, pasta, seis libras.

Diccionario Italiano, Latin y Franses de ANTONINI, dos tomos en quarto, pasta, cinco libras.

VINNIUS: Castigatus, con notas de Sala y el Dro. Español, dos tomos, quarto, pasta, tres libras quatro sueldos.

Diccionario Español y Francés, de SOBRINO, dos tomos en quarto, pasta, quatro libras. 
ORACIO, ad usum Delfini, dos tomos en quarto, pasta, quatro libras. CALATAYUD: Doctrinas Prácticas, un tomo en folio, una libra.

NEBRIJA: Diccionario Latino, en folio, diez sueldos.

NIERAMBELO: Obras, dos tomos en folio, dos libras.

MARIANA: Historia de España, por la Biblioteca de Madrid año ochenta y dos, dos tomos en folio, seis libras.

VAN ESPEN: Iusus Eclesiasticum, tres tomos en folio, seis libras.

COVARRUBIAS: Maximas de recursos de fuerzas, en Madrid, pasta, quatro libras.

Instituciones del Dro. de Castilla, por AZO, un tomo, en pasta, quarto, una libra.

SALUSTIO y algunas Oraciones de CICERON, traducidas, un tomo en quarto, pasta, una libra.

Oficio de Semana Santa, latín y castellano en Amberes, trece sueldos y quatro.

Oficio de la Semana del Corpus, en Amberes, trece sueldos y quatro.

Oficio de San Nicolás, trece sueldos y cuatro.

SAN AGUSTIN: Confesiones y meditaciones, dos tomos, octavo, traducidos al castellano por Ribadeneira, diez y seis sueldos".

El inventario establece el 116 el total de tomos de que constaría la biblioteca; aparte de otros de los que no se da referencia explícita del número de volúmenes, lo que sin duda harla aumentar la cifra anterior.

Al ocuparnos ahora del pormenor de los temas tratados en dichas obras, podemos resumirlos globalmente en los siguientes apartados:

\section{1.-Estudios historicos.}

Dentro de la sección de libros de Historia, disciplina que gozó de especial favor entre los ilustrados, cabe destacar títulos como La Monarquía Ebrea, del Marqués de San Felipe (dos tomos) y la Historia de España, del Padre Mariana.

Comenzando por la obra del Marqués de San Felipe, creemos que el ejemplar en cuestión lo podemos identificar no con la primera edición de la obra, publicada en Génova en 1719 y en 4 tomos, sino con algunas de las ediciones madrileñas aparecidas en el siglo XVIII, todas ellas en dos tomos.

A pesar de su título es una obra, como ha señalado el historiador Carlos Seco, moralista y doctrinaria, pero que sin embargo deja traslucir el método del criticismo histórico(3). Llegados a este punto conviene no olvidar las decisivas aportaciones que en la renovación de la metodología 
historica llevan a cabo personajes de la talla de Nicolás Antonio, Mondéjar y, avanzado el siglo, Gregorio Mayáns.

En segundo lugar es preciso aludir al libro del P. Mariana. Su Historia de España, para los ilustrados españoles, se consideró como uno de los textos de más valor para el conocimiento de nuestra historia. Recordemos, a modo de ejemplo, la recomendación hecha por Jovellanos de la obra del P. Mariana al colegio de Calatrava, como recoge Sarrailh(4). Pero aún hay más, Gregorio Mayáns había realizado la introducción de dicho libro en una de las ediciones aparecidas en el siglo XVIII, lo que resulta especialmente significativo(5).

\section{2.-Interés de los llustrados por la pedagogía y la enseñanza.}

La preocupación por la reforma de la enseñanza y de la educación, necesarias para una gradual transformación del país, tan querida por los ilustrados, se concreta aquí en los trabajos de Barbadiño y de Rollin.

El libro de Luis Antonio Verney, más conocido por el "Barbadiño», titulado Verdadero método de estudiar, se tradujo al español en 1760 . En él se hace una demoledora crítica de los métodos rutinarios de enseñanza en España, particularmente en lo que respecta a los estudios universitarios(6). Esta postura no será compartida por algunos eruditos, como Feijoo, lo que supondrá inevitablemente un enfrentamiento entre ambos. De igual modo, Mayáns y en general el llamado círculo valenciano se opondrán resueltamente a los criterios mantenidos por el benedictino(7). Ello evidencia de manera incuestionable la proximidad ideológica existente entre Barbadiño y Mayáns. Añadiremos a lo dicho que la obra De re Logica, del mismo autor portugués, fue publicada por el valenciano Juan Bautista Muñoz en 1769, el cual, al decir de Mestre, resultaba del agrado de D. Gregorio(8).

Es curioso, por otro lado, que el propio Barbadiño al trazar su plan de estudios escolares y universitarios, en los que sorprendentemente propone una serie de reformas pedagógicas de la más absoluta contemporaneidad, como la recomendación de clases poco numerosas, métodos activos, etc., habla también de la educación de las mujeres recogiendo la opinión de Fenellón y Rollin(9). Cabe, por tanto, pensar que los textos de Rollin citados en el inventario se enmarquen dentro de una misma órbita de pensamiento. De todas formas es posible que una de las obras que el catálogo asigna a Rollin, Historia del Cielo, no corresponda a dicho autor. Acaso quiera referirse a la obra del mismo título del abad de Pluche, así mismo en dos tomos y traducida por el fraile Pedro Rodríguez Morzo.

\section{3.-Desarrollo de las Ciencias.}

Las posiciones críticas y reformistas del siglo XVIII afectarán considerablemente a las disciplinas científicas. En este terreno se advierte un 
sustancial esfuerzo de apertura y acogimiento de la ciencia moderna. Se constata, en efecto, un decidido afán por estar al corriente de las novedades del exterior, para lo cual, en ocasiones, se presentará especial atención por parte de los gobernantes a la formación de nuestros científicos en los centros más prestigiosos del extranjero.

De igual modo los poderes públicos se esforzarán en desarrollar en nuestra patria toda una serie de proyectos científicos, si bien los resultados no fueron todo lo positivo que cabria esperar.

Ciñéndonos al tema que nos ocupa hemos de decir que el interés por los saberes científicos en nuestro autor queda reflejado por los tratados que aparecen en su biblioteca. Asi encontramos títulos tan sugestivos como el Compendio Matemático, de Tosca, Ensayos para la historia de artes y siensias (sic), Diccionario Geográfico, de Echart, Espectáculo de la Naturaleza, etc.

Con respecto a la obra de Tosca importa subrayar el hecho de que ésta, al igual que la de Newton-salvando, es lógico, la superior categoría científica del inglés - fueron propuestas en las reformas de la Universidad de Alcalá. Su modernidad, en el caso de la obra del valenciano, viene dada en función del método científico empleado. De todas formas la personalidad de Tosca presenta ciertas lagunas en su proceso formativo, tal como se desprende del desconocimiento que tenía de los estudios llevados a cabo por matemáticos de su misma época, crítica que ya en el siglo XVIII le hizo uno de nuestros más prestigiosos matemáticos: Jorge Juan(10).

Naturalmente no podían faltar obras de divulgación. A título de ejemplo señalemos el Espectáculo de la Naturaleza, del abate Noel Antoine Pluche, sin duda una de las publicaciones que más éxito obtuvieron sobre todo en Francia, su país de origen. La obra, publicada en 1732, resultó ciertamente ambiciosa si nos atenemos al número de volúmenes de que constaba, nada menos que 16 tomos. En España apareció por vez primera en 1753, y hay constancia de que se publicaron tres ediciones más hasta finales del siglo(11). El autor se esforzo, de ahi su principal mérito, en difundir y divulgar los últimos descubrimientos científicos, poniéndolos al alcance de más amplias capas de población.

\section{4.-Difusion del espiritu humanista.}

El término "humanista» en realidad habrá que entenderlo en una doble acepción. De una parte aludirá directamente al estudio de la antigüedad eclesiástica y obviamente de sus más ilustres representantes. En segundo lugar, para los ilustrados españoles de la XVIII centuria significará una revalorización de nuestros grandes humanistas del siglo XVI, como Vives o Nebrija.

Ahora bien, en este proceso evocador del pensamiento humanista lo 
que se buscaba, como argumenta Edith Helman, era sobre todo establecer un medio de reformar al hombre, de formar de una manera totalmente nueva su espiritu, dándole visión crítica e independencia(12). En suma, cambiar la sociedad mediante las "luces" de la razón.

Por otra parte tengamos en cuenta, y en ello ha insistido Mestre, que frente al influjo de la cultura francesa observable en algunos reformistas españoles, como Feijoo, otros, por el contrario-es el caso de los valencianos-, muestran un mayor espíritu de exaltación de las glorias nacionales(13).

Como es natural en el catálogo que comentamos hallamos títulos que entran de lleno en este apartado.

Que Nicolás Pró estuvo compenetrado con la cultura clásica es algo evidente si se considera la lista de autores citados en el inventario: Marcial, Virgilio, Cicerón, Horacio y Salustio. Debe hacerse notar que en este punto el Sr. Pró enlaza con la línea de investigación implantada por el deán Martí al propugnar el estudio y conocimiento de las grandes figuras del mundo clásico.

Idéntica exigencia en la valoración del mundo greco-latino mostrará Mayáns, cuya admiración por el deán es de sobra conocida.

Para cubrir estos objetivos-dar a conocer los textos clásicos-se requería necesariamente emprender la urgente tarea de traducirlos a la lengua española, debido a la escasez de ediciones en nuestra lengua.

Este mismo entusiasmo mostrarán los eruditos españoles del siglo XVIII por la recuperación de nuestros más destacados intelectuales del Renacimiento. A pesar de que en el inventario no aparecen los nombres de Juan Luis Vives, Fray Luis de León o Cervantes, sí se citan, sin embargo, los de Covarrubias y Nebrija. Precisamente de este último autor habia edjtado Gregorio Mayáns algunas de sus publicaciones.

\section{5.-Desarrollo de los estudios de Derecho y Jurisprudencia.}

En el proceso de transformación cultural español los estudios de las disciplinas jurídicas ocuparán un lugar destacado. En consecuencia los ilustrados no dudarán en aconsejar los textos de mayor categoría científica para el conocimiento de dichas materias. Pero tan buenos propósitos se enfrentaban a una dura realidad, y es que lamentablemente España no contaba apenas con tratados de contenido jurídico. De ahí que quienes se interesaran por estos temas tuvieran que acudir de manera obligada a los grandes textos escritos por extranjeros, como Grocio, Puffendorf, etc. Semejantes declaraciones no impiden afirmar la existencia de obras escritas por españoles. En este sentido es preciso hacer mención forzosa de las Instituciones de Derecho de Castilla, que el catálogo atribuye a Azo. 
La obra en cuestión se publicó en 1770 por dos jurisconsultos: Ignacio Jordán de Asso y del Río, y Miguel de Manuel y Rodríguez.

En ella se daba a conocer los origenes de la legislación española, aludiendo especialmente al destacado papel otorgado a las Cortes, una de cuyas funciones consistía en limitar el poder reak(14). Otro título, igualmente, afecta a este apartado dedicado a temas jurídicos; nos referimos al que el catálogo cita como Vinnius Castigatus, con notas de Sala y el Derecho español. Se trata del jurisconsulto holandés Arnold Vinnen (1588-1657), a quien Sempere Guarinos consideraba como un hereje legista, pero que, no obstante, las Facultades españolas no tuvieron reparo en admitir sus obras(15).

Tanto el Vinnius como el Derecho Español se enmarcan dentro de la especialidad de Mayáns.

Conviene así mismo recordar que los títulos anteriormente reseñados no agotan el caudal de conocimientos de D. Nicolás Pró en los temas jurídicos. Sin extendernos en más consideraciones sólo queremos añadir un dato que resulta revelador de lo que venimos afirmando. Consiste en un testimonio epistolar inédito fechado en 4 de junio de 1779, por el cual D. Simón Gómez Pérez, agente de la ciudad de Alicante en la capital de España, contestaba desde Madrid al Sr. Pró en estos términos:

"Muy Sr. mío: Los libros Hugo Grocio, Derecho de la Guerra y de la Paz está prohibido. También lo está Montesquieu sus obras, y el Espíritu de las Leyes. Se me dice que está prohibido Bruckero, Historia Crítica de la Filosofia, aunque con alguna duda y que me lo dirán en breve con toda certeza para dar a V. M. aviso ciertow(16).

El interés del documento estriba en que curiosamente los autores solicitados por el secretario municipal alicantino son los mismos que los aconsejados en numerosas ocasiones por Mayáns.

\section{6.-Religiosidad de los ilustrados españoles.}

De este último epígrafe forma parte el conjunto más numeroso de libros que componen el inventario del Sr. Pró. Ello patentiza bien a las claras su profunda religiosidad, aunque entendida ésta de un modo más hondo y vivencial que ritualista. Actitud que en nada difiere a la mostrada por Mayáns.

En la nómina de libros de tema religioso acumulados por el alicantino aparecen autores tales como Bossuet, San Agustín, etc. También obras de idéntico contenido: Historia del establecimiento de la Iglesia, Oficio de Semana Santa, Oficio del Corpus, etc. Pero veamos el especial significado de algunos de estos textos, así como la actitud manifestada en orden a una saludable y, por otra parte, necesaria renovación eclesiástica. 
Es un hecho de sobra conocido que los hombres de la llustración española, al contrario que en Francia, por ejemplo, supieron conciliar armonicamente su fe profunda con la exigencia propia del siglo: la crítica y el racionalismo. Esto les llevará en ocasiones a enfrentamientos con la Iglesia, al criticar posturas y actitudes eclesiásticas no acordes con la mentalidad reformadora de los ilustrados, aunque, eso sí, dentro de la más estricta ortodoxia.

Una de dichas cuestiones, y no desdeñable precisamente, consistía en deslindar la esfera de actuación del poder eclesiástico con respecto del poder civil, excesivamente identificados. En este caso uno de los autores que más decididamente se inclinaban por separar las competencias de ambos poderes era Bossuet. Su galicanismo, como establece Mestre al analizar el interés despertado en Mayáns por la obra del célebre orador y escritor francés, se centra en dos puntos cruciales: la independencia de la autoridad temporal frente a la potestad espiritual y, de otra parte, su concepto acerca de los principios que limitaban el ejercicio de la autoridad del Papa(17). Tales cuestiones aparecen y se desarrollan en los seis tomos de su Potestad Eclesiástica.

Sin entrar a discutir su posible adscripción a la corriente jansenista, ni siquiera plantearnos la propia consideración del término, lo que sí parece estar fuera de duda es que Bossuet es uno de los que manifiestan una decidida hostilidad antijesuítica.

De quien bien puede afirmarse su condición jansenista es de Van Espen, autor que, al igual que Bossuet, interesó e influyó grandemente en Mayáns. Sabemos, según declara Mestre, que el valenciano se convertirá en uno de los más fervientes propagadores de la obra del belga. Además, y esto nos interesa, procurará que sus amigos lo lean(18).

Todo parece indicar, y con esto concluímos, que D. Nicolás Pro, una vez analizada brevemente su biblioteca, estaba familiarizado con las tendencias culturales más avanzadas del siglo. Uno de los factores determinantes que le moverán a ello será, justo es decirlo, el influjo de uno de los más prestigiosos ilustrados: D. Gregorio Mayáns. 


\section{NOTAS:}

(1) Archivo Municipal de Alicante. Legajo 39. Arm. 3. Diversorum n. ${ }^{\circ} 81$. Año 1787: «inventario de los Bienes que han quedado por muerte de D. Nicolás Pró, antes Bayona, escrivano primero que fue del Ilte. Ayuntamiento de esa ciudadn.

(2) Un interesante estudio sobre este tema, en M. Deforneaux: Inquisición y censura de libros en la España del siglo XVIII, Madrid, 1973.

(3) Cf. San Felipe, Marqués de: Comentarios de la Guerra de España e historia de su rey Felipe V el Animos. Estudio preliminar de D. Carlos Seco Serrano, Biblioteca de Autores Españoles, tomo 99, Madrid, 1957., pp. LXV-LXVIII.

(4) Cf. Serrailh, Jean: La España Ilustrada de la segunda mitad del siglo XVIII, Fondo de Cultura Económica, Madrid, 1974, p. 399.

(5) Vid. Gregorio Mayáns y Siscar: Epistolario; transcripción y notas de Antonio Mestre. Publicaciones del Ayuntamiento de Oliva, Valencia 1972-1973. Tomo III., p. XVIII.

(6) Cf. Sarrailh, J.: Op. cit., p. 199.

(7) Cf. Mestre, A.: Historia, fueros y actitudes politicas. Mayáns y la historiografia del XVIII. Publicaciones del Ayuntamiento de Oliva, Valencia, 1970, p. 82.

(8) Ibid., p. 329.

(9) Cf. Sarrailh, J.: Op. cit., p. 201.

(10) Vid. Gregorio Mayáns y Siscar: Epistolario... Tomo II, p. XVI.

(11) Cf. Herr, Richard: España y la revolución del siglo XVIII, Madrid, 1975, p. 35; también en Sarrailh, J.: Op. cit., p. 201.

(12) Cf. Hellman, Edith: Jovellanos y Goya, Madrid, Taurus, 1970, pp. 15-30.

(13) Este aspecto ha sido ampliamente abordado por Antonio Mestre. Véase de este autor: "Los origenes de la llustracion", extra de Historia 16, diciembre, 1978, pp. 62-68; Id.: Historia, fueros..., p. 34; Id.: Despotismo e llustración en España, Barcelona, 1976, pp. 36-40.

(14) Cf. Herr, R.: Op. cit., p. 282, y Sarrailh, J.: Op. cit., pp. 164 y 578.

(15) Cf. Guarinos, Juan Sempere: Ensayo de una biblioteca española de los mejores escritores del reinado de Carlos III, Madrid, 1785-1789, tomo II, p. 3.

(16) Archivo Municipal de Alicante. Cartas recibidas del año 1779. Libro 35. Arm. 12, fol. 58.

(17) Cf. Mestre, A.: Ilustración y Reforma de la Iglesia. Pensamiento politico-religiosos de D. Gregorio Mayáns y Siscar (1699-1781). Publicaciones del Ayuntamiento de Oliva, Valencia, 1968, p. 367.

(18) Cf. Mestre, A.: Despotismo e Ilustración..., p. 191. 